\title{
HOMOGENEIZACIÓN BIOCULTURAL: EXOTIZACIÓN DEL PAISAJE FEMENINO LATINOAMERICANO
}

ANGELINA PAREDES CASTELLANOS ${ }^{\mathrm{a}} \&$ RICARDO ROZZI

\section{RESUMEN}

El lenguaje colonial "del ojo imperial" sobre América Latina se resume en un mito exótico sobre el paisaje, que hoy se conjuga con la globalización Occidental en su encrucijada ecológica. América Latina es un signo hermenéutico clave de análisis, debido a que expone la raíz ideológica estética que acompaña a la uniformización del paisaje con una sola semántica objetiva basada en una ideología exotista. El lado estético que resalta en la pregunta por la naturaleza de la "América exótica" revela la importancia de valorar una hermenéutica alternativa, ecológica, estética y post-exótica para re-pensar la Tierra Nueva o el Nuevo Mundo, América. Ancestralmente y, hasta hoy llamada, Pachamama en los Andes del sur.

PALABRAS CLAVE: América Latina, Exotismo, Geografía Femenina, Ecología.

\section{BIOCULTURAL HOMOGENIZATION: EXOTISM OF THE FEMENINE LANDSCAPE OF LATIN AMERICA}

\section{ABSTRACT}

The colonial language "of the Imperial Eye" on Latin America is summarized in an "Exotic Myth about the landscape", which today is combined with the occidental globalization at its ecological crossroads. Latin America is a key hermeneutic sign of analysis, because exposes the aesthetic ideological root that accompanies this uniformity of the landscape with a single objective semantics based on an exotist ideology. The aesthetic side that stands out in the question of the nature of "exotic America" reveals the importance of valuing an alternative, ecological, aesthetic and post-modern-exotic hermeneutic to re-think the new Earth or the New World, America. Ancestrally and until today called Pachamama in the southern Andes.

KEY WORDS: Latin America, Exoticism, Feminine geography, Ecology.

a Doctorante, Instituto de Investigaciones Filosóficas Luis Villoro, Universidad Michoacana de San Nicolás de Hidalgo, Morelia, Michoacán, México. $X$ angelinacastell@gmail.com

b Department of Philosophy and Religion y Department of Biological Sciences, University of North Texas, USA; Centro Universitario Puerto Williams, Universidad de Magallanes; Instituto de Ecología y Biodiversidad (IEB) Chile. 


\section{"AMÉRICA LATINA EXÓTICA": PAISAJE Y CUERPO}

Víctor Segalen afirma en su Ensayo Sobre el Exotismo (1989) que él "no hablará sobre palmeras, mujeres, indígenas, camellos o paraísos sino sobre el sentimiento de lo diverso sin decirnos qué es lo diverso o qué entiende él por exotismo dando por obvio lo no tan obvio" (Segalen, 1989, p. 62). A inicios del siglo XX, este etnógrafo y escritor francés inició una crítica al exotismo abriendo una interrogación que no llegó a cerrarse en su época (Paredes, 2017). En la década de 1970, el crítico literario y activista palestino-estadounidense Edward Said, en la misma tendencia, nos dice en su texto Orientalismo (2016), que "no hablará acerca de misterios, encantamientos, enamoramientos entre nativas y foráneos o promesas, y se enfocará solamente en el análisis de cómo se perpetúa en el ámbito del conocimiento y de la cultura occidental (la literatura, la ciencia, la política, las universidades, etc.)" una falsa imagen de Oriente (Said, 2016, p. 447).

Segalen y Said generan un discurso crítico sobre la discriminación y la xenofobia sobre "el otro", el "extranjero del sur", sobre el supuesto "tercer mundo" elaborado desde el "primer mundo", sin entregar mayores alternativas epistemológicas, estéticas o geográficas.

\section{Sobre promesas eco-feministas}

En contraste, en este texto sí hablaremos de los temas que ambos autores han dejado de lado: paisajes-geográficos-femeninos, indígenas, enamoramientos entre europeos con nativas americanas, encuentros estéticos, el misterio, el encantamiento estético sobre los "paisajes exóticos" y los cuerpos desnudos. En el presente texto estos temas no son considerados asuntos menores. Así, se les otorga una merecida problematización que nos aproxime a mirar

1 En la filosofía de Hans-Georg Gadamer, la hermenéutica se refiere a la teoría de la verdad y el método que expresa la universalización del fenómeno interpretativo desde la concreta y personal historicidad.

2 Said, 2016, 339-431. En su Orientalismo, Said criticó el orientalismo, que construía una constelación de falsos prejuicios en la forma que la cultura occidental interpreta alternativas hermenéuticas ${ }^{1}$ a la exotización del paisaje, de la naturaleza y de los cuerpos en el contexto de América Latina, criticando la idea romántica basada en la "América exótica" donde geografía, ambiente y cuerpos aparecen exotizados por "el ojo imperial", que los ha asumido como al "servicio de" para "un placer desinteresado".

\section{Sobre "camellos"}

Said coopera con el orientalismo ${ }^{2}$ que critica al no dar alternativas a la imagen del "Oriente exótico". En su libro Orientalismo (Said, 2016), nos ofrece una lista de autores que nos ayudarían a comprender qué es el Oriente. Critica los prejuicios eurocéntricos contra las culturas orientales y denuncia las imágenes falsas y romantizadas que sobre Asia y el Medio Oriente ha elaborado la cultura occidental. Este estereotipo ha provisto una justificación para las ambiciones coloniales e imperiales de Occidente en Oriente. Esta representación distorsionada del Oriente promueve, junto con su explotación imperial, una homogeneización biocultural (sensu Rozzi, 2013).

A diferencia del "Oriente exótico", la "América exótica" tiene hoy teorías y elementos culturales que permiten una crítica de la razón exótica del "ojo imperial" occidental, que inventó, narró, desdibujo, representó e impuso un discurso tergiversado desde un lenguaje exotista a "lo femenino", como una enemiga, una otra amenazante, inferior y servil, tanto en el ámbito corporal como en el ambiental. Al mismo tiempo, nuevos planteamientos ofrecen las bases para elaborar una hermenéutica estética alternativa diferente a la del "ojo colonialista y exotista imperial". Más radicalmente, se propone una hermenéutica eco-epistemológica postexótica, crítica de la hermenéutica negativa o de la maldición del lenguaje exotista resultante

las culturas orientales. Said denunció los prejuicios eurocéntricos contra los pueblos árabes-islámicos y su cultura, y la larga tradición de imágenes falsas sobre Asia y el Medio Oriente. Denunció que estas imágenes han servido de justificación implícita a las ambiciones coloniales e imperiales de Occidente sobre Oriente. 
del expansionismo colonial europeo y del nuevo imperialismo posmoderno, representado en la homogeneización biocultural o exotización biocultural de la actual globalización occidental sobre el paisaje, la geografía ambiental y corporal de las regiones. Porque hoy un nuevo exotismo ambiental y corporal aparecen bajo los nuevos "ojos imperiales" sobre el continente.

\section{Sobre "palmeras", platos y reptiles}

Las figuras del "mesero y la prostituta" son constantemente citadas en la obra del artista mexicano-costarricense Joaquín Rodríguez del Paso (Chavarría, 2013, p. 13; Fig. 1) para mostrarnos un supuesto carácter "servil y entreguista" con las que falsamente se estereotipan al hombre y a la mujer latinoamericanos, respectivamente. La "mujer ofrecida" en el gran plato denuncia la imagen estereotipada y falsa de la mujer latinoamericana desde la idea de un cuerpo femenino exótico ofrecido para el deleite, como parte del imaginario exótico-femenino sobre el continente. De la misma forma, la figura de la mujer sobre el reptil puede hacer referencia a la imagen exótica de una "mujer-salvaje", la del Nuevo Mundo, también considerado un mundo-paisaje salvaje y servil. No es casual que América Latina sea uno de los destinos turísticos sexuales donde se revela una forma peculiar de ver al cuerpo femenino: lo que se busca es un "cuerpo femino como objeto" al servicio de un "disfrute desinteresado". El cuerpo femenino es visto como un fetiche exótico sobre-sexualizado y el cuerpo masculino como un objeto servil. Esta obra nos habla de una belleza exótica como parte del mito exótico de América Latina, es decir, una interpretación estética del "ojo imperial" sobre un paisaje femenino desde su particular interpretación estética de dominio.

\section{“Ojos imperiales” sobre la} geografía de América

Desde el llamado "Descubrimiento (o invención) de América" (cfr. Mignolo, 2007) hasta el siglo XVIII, la idea romántica de la "América

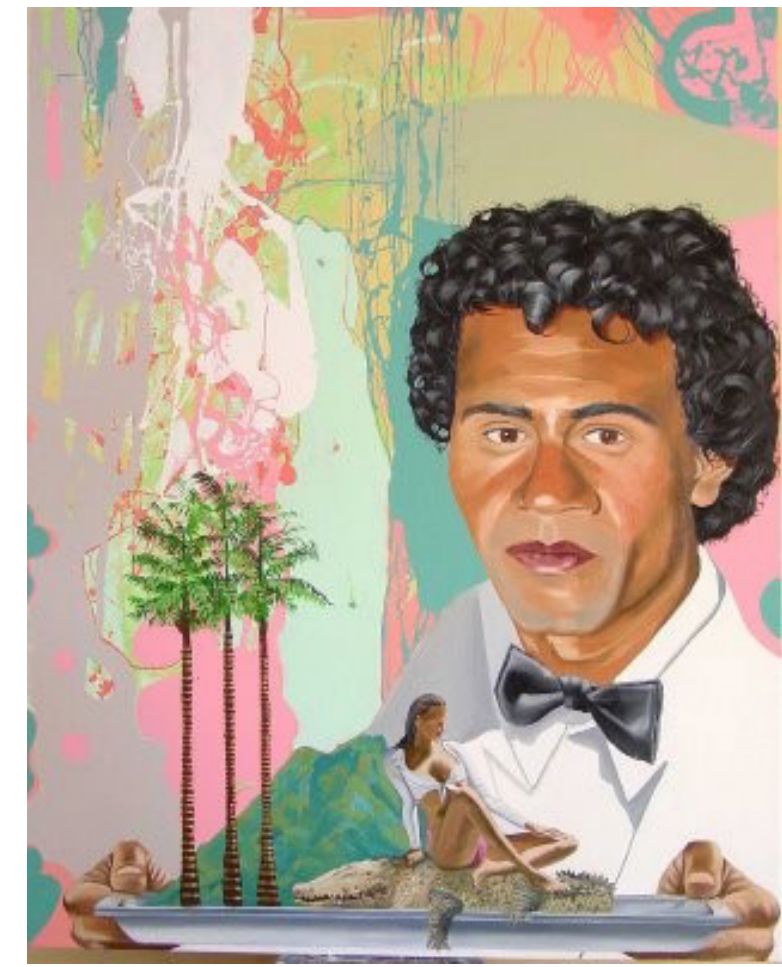

Fig. 1. Joaquín Rodríguez del Paso, "Biodiversidad" Costa Rica, 2008, (Chavarría, 2013, p. 13). Reproducido con la autorización de la familia. En: http://joaquinrdelpaso.com/

exótica" estuvo figurada por la obra de europeos: conquistadores, religiosos, naturalistas, científicos, dibujantes y pintores, entre otros. Estos creadores de una representación colonialista y exotista de América mantuvieron una visión centrada en la enorme riqueza ambiental y social, pensada para ser explotada ${ }^{3}$. A finales del siglo XIX y a principios del siglo XX, nuevos viajeros europeos con largas estadías en Sudamérica reforzaron la idea colonialista de "la América Latina exótica" desde ciertas representaciones estereotipadas: "el paisaje salvaje", "la naturaleza virginalprimordial", con conceptos como el "buen salvaje" hasta "el caníbal". La exotización de América del Sur realizada por buena parte de la historia del cristianismo-sacerdotal en la región puede ser llamada El mito exótico sobre América Latina, con la naturaleza representada como una virgen intocada, salvaje, servil, exhibida o una máquina dormida. 
"El encuentro exótico entre la nativa y el foráneo"

La cuestión local y continental es abordada por la lingüista canadiense Mary Louise Pratt (2010), quien plantea que el paisaje de América recibe su "primera" interpretación semántica en la impresión estético-negativa en el encuentro del europeo con el paisaje recién conquistado del Nuevo Mundo, llamado posteriormente América. Para los primeros "ojos imperiales" -masculinos y patriarcales- la visión de la naturaleza de América fue siempre la de posesión y de explotación constante. El mito virginal de una naturaleza femenina joven, intocada, negligente, salvaje, exuberante, rebelde, amazónica, transformada en una "América muerta y muda" (Pratt, 2010), proveyó el justificante ideológico y argumentativo para una intervención progresista de cierta masculinidad occidental sin límites. Su lado estético hermenéutico fue la imagen de una geografía femenina deformada y desdibujada como un "montaje" salvaje para el control y el ultraje.

El pensador uruguayo Eduardo Gudynas (2009) plantea que desde la llegada de los primeros conquistadores hasta hoy, para nuevos actores colonialistas y modernistas (externos e internos), la naturaleza latinoamericana ha sido vista como la "gran canasta de recursos naturales" y "corporales". Destaca la importancia del tema del cuerpo incluido en esta "canasta" (Paredes, 2017). Ningún obstáculo impedía a los conquistadores del pasado, ni impide al hombre del presente, bajo un régimen económico occidental, la violación explotadora constante de la tierra americana bajo conceptos objetivos y cosificantes de la naturaleza. El periodista y escritor uruguayo Eduardo Galeano (2011) nos recuerda la manera en que la naturaleza latinoamericana y sus habitantes fueron interpretados como un "gran tesoro" que ofrecía inmensas riquezas.

Pratt y el ecofeminismo identifican una idea coincidente y constante entre los foráneos europeos y los nativos acerca de la asociación de la naturaleza americana con lo femenino. Esta asociación nos lleva a relacionar el tema de una geografía femenina con un mapa-mujer (Fig. 2). Los conquistadores europeos forjaron una imagen de la naturaleza geográfica femenina bajo su

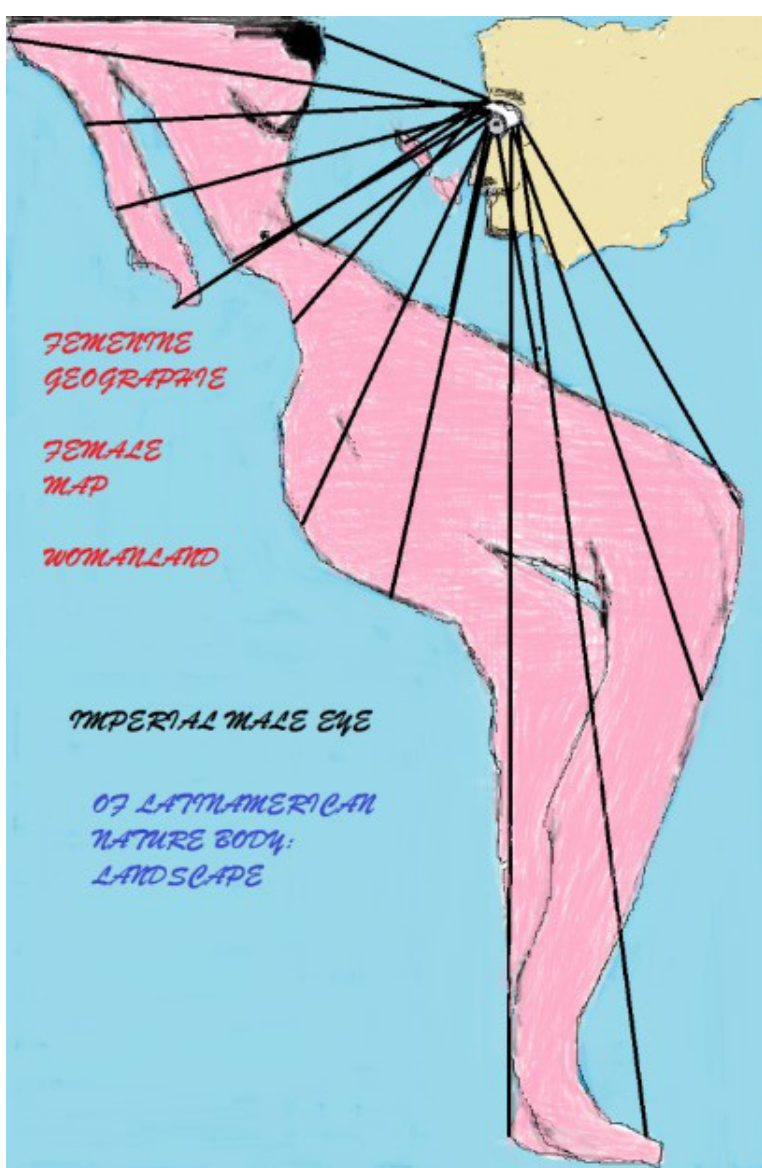

Fig. 2. "Ojos imperiales sobre un mapa femenino" de Angelina Paredes (2017).

concepto de control y dominio. En contraste, la "mirada otra" de los nativos y las nativas considera hasta hoy a la misma geografía femenina desde una hermenéutica de la Madre Tierra y no desde la noción de dominio.

\section{Sobre "enamoramientos" \\ entre nativas y foráneos}

No sólo el paisaje de la naturaleza americana fue objeto de dominio, también lo fue el paisajecuerpo de la mujer nativa. Por lo tanto, el tema del cuerpo semidesnudo de la mujer nativa americana es un punto clave para comprender el aspecto más amplio de la geografía americana en su proyección corporal femenina de dominio. Ambas geografías, ambiental y corporal, son vistas e interpretadas bajo los mismos "ojos imperiales" patriarcales de dominio 
occidental. El impacto del imaginario de una estética negativa sobre toda una zona geográfica corporal se expresa en el estereotipo del cuerpo de la mujer en el exotismo sobre lo femenino del sur: en la imagen de la mujer latinoamericana como "exótica".

La hermenéutica de la visión dicotómica cristiana-sacerdotal masculinista de lo femenino, fue impuesta semánticamente sobre ambas: la naturaleza americana y la mujer nativa. Mujer y paisaje de América Latina bien pueden ser intercambiables para comprender la historia violenta del drama de la naturaleza de América representado por el encuentro del europeo con la nativa americana. La activista y pensadora feminista decolonial Yuderkys Espinosa Miñoso plantea que:

el relato del hombre blanco "enamorado" de la esclava indígena o africana, oculta la verdad del encuentro sexual obligatorio, de la producción de un cuerpo femenino al servicio de la empresa colonial y patriarcal. La naturalización de la mujer nativa o esclava como parte del paisaje conquistado es un efecto no sólo de la razón colonizadora sino de la razón patriarcal y heteronormativa. Es pues que ambas razones más que articuladas han sido parte de lo mismo, son parte de la misma trama de dominio. No es posible pensar la una sin la otra: la historia de la invasión europea a estas tierras también ha sido la historia de la invasión del cuerpo violable de las mujeres originarias (Espinosa, 2009).

\section{Sobre mujeres}

La novela Iracema, del escritor brasileño José Martiniano de Alencar, sobre la mujer nativa enamorada del portugués ha sido considerada la madre fundadora de una nueva cultura mestiza hacia el futuro (de Alencar, 2000). Nacido en 1829, de Alencar tuvo una participación en política y literatura que inauguró una visión nacional de un nuevo mundo. En México, la historiadora y escritora Fernanda Núñez Becerra ha criticado cómo la Malinche (Marina) ${ }^{4}$ ha sido vista como una "puta", una traidora que se entregó al conquistador europeo. Dicha interpretación negativa y exotista

4 La Malinche, o doña Marina, nativa de la etnia nahuatl, fue la intérprete y amante del conquistador Hernán Cortés. reitera una y otra vez la imagen desdibujada implícita tanto del paisaje corporal femenino geográfico como del paisaje femenino corporal (Núñez, 2002). Esta hermenéutica exotista de la maldición y del dominio sobre lo femenino del sur latinoamericano, no hace una justicia interpretativa y recae una y otra vez en la hermenéutica colonialista del insulto y del dominio. En la cultura mexicana, el exotismo sobre lo femenino suele no ser criticado sino asumido como parte del colonialismo exotista interno patriarcal como copia del Occidente.

Desde el exotismo, tanto la mujer nativa americana como la geografía americana, respectivamente, han sido estereotipadas. La primera, como una mujer exótica o prostituta, una mujer-cuerpo cosificado, servil, y esclavizado para el ultraje; la segunda, como una gran geografía ultrajada, esclavizada y saqueada: "la gran puta América”. Ante esto, una hermenéutica alternativa y femenina del sur "contrarresta" dicha imagen deformante del paisaje femenino (Paredes, 2017). La metáfora de las "venas abiertas de América Latina" (Galeano, 2011) alude al vientre violentado y saqueado de la gran naturaleza latinoamericana, y especialmente a la herida colonial imperial. La imagen del daño ecológico hecho al cuerpo geográfico de la naturaleza latinoamericana puede complementarse agregando otra metáfora desde el particular aspecto femenino-corporal de la región: "las piernas abiertas del cuerpo de América Latina".

\section{Críticas y alternativas al exotismo biocultural}

A mediados del siglo XX y a comienzos del siglo XXI, principalmente en Brasil, Chile, Bolivia y Ecuador, se empieza a gestar el cambio de la imagen deformada de la "América exótica". Esta revalorización de la naturaleza y de las sociedades latinoamericanas que hablan desde sí mismas, se realiza desde una hermenéutica ecológica del reconocimiento de la alteridad ${ }^{5}$ post-exótica.

\section{Sobre misterios: "el caníbal"}

En el caso de Brasil, país que posee una de las mayores biodiversidades de flora y fauna del planeta (Primack et al. 2006), nace el movimiento

Alteridad es la condición de ser otro. 
artístico e intelectual Antropofagia con uno de sus lemas: "tupí or not tupí"6, haciendo referencia al canon occidental filosófico del ser o no ser (Giraudo, 2016, p. 11). Desde este movimiento, inaugurado en la década de 1920, se empieza a re-dibujar la nueva imagen de la región y así se cuestiona el canon cultural estético colonial europeo y su supuesta superioridad cultural. El movimiento estético brasileño asume la acusación y subvierte la idea del canibalismo, pues la lleva a una intelectualización tal que la hace parte de la identidad del lugar que vuelve a sus raíces, a su tradición y a sus mitos de culturas originarias.

Abaporu es un óleo que refleja el postexotismo desde el arte, y es un término tupí que significa hombre (abá) que come (u) gente (poro). La artista brasilera Tarsila do Amaral lo pintó en 1928 para el escritor Oswald de Andrade, uno de los fundadores del modernismo brasileño y autor del Manifiesto Antropofagia (1928). Una interpretación de la pintura es que a raíz de la depredación de su propia naturaleza, el sujeto moderno occidental es un caníbal moderno de sí mismo, que ha llegado a ser capaz de su propia autodestrucción. La segunda pintura más emblemática del movimiento Antropofagia tiene como elementos una gran figura femenina con uno de sus senos resaltados, y una figura masculina disminuida. La figura ampliada de la mujer rememora las antiguas visiones sagradas de lo femenino en su relación estrecha con la tierra. El hombre y la mujer están representados con enormes pies y piernas, mientras que sus cabezas -lugar donde la razón occidental representa el centro y dominio sobre lo corporal y emocionalson minúsculas. Sus corporalidades están envueltas en el verdor de la naturaleza tropical. El cuerpo está resaltado en ambas pinturas, haciéndonos ver la importancia del tema corporal para el estudio de la naturaleza en América Latina desde una mirada no exotista del cuerpo y de la Tierra.

En el transcurso del siglo XX, las ideas filosóficas ambientales de pensadores brasileños han llegado a formar parte de este nuevo espíritu centrado en la importancia de replantear la naturaleza en la identidad regional. El filósofo

6 Los tupí eran un grupo de pueblos originarios de la costa de Brasil y de grandes sectores de la selva amazónica. Los pueblos tupí estaban conformados por etnias que brasileño Mauro Grün reflexiona sobre el tema ecológico y la estética desde una hermenéutica de la naturaleza del filósofo alemán HansGeorg Gadamer. Ambos señalan el peligro del antropocentrismo y critican una interpretación que consiste en la relación de superioridad establecida por el hombre (occidental y moderno) sobre la naturaleza (geografía americana, latinoamericana). El primero es concebido como el amo totalitarista que debe dominar la naturaleza para su propio provecho. Grün llama a esto antropofascismo (Grün, 2012). La diferencia es que Grün sí añade la preocupación por la visión femenina de la Tierra, propia de la identidad latinoamericana, pero desde una perspectiva centrada en un posible ecofascismo. Según Grün, suponer a la naturaleza como un gran sujeto femenino nos puede llevar a disminuir al hombre y, por lo tanto, a objetivarlo y a eliminarlo, entre otros aspectos, como sujeto de derechos. En concordancia con Gadamer, Grün recomienda pensar a la naturaleza desde la ética como "lo otro", la otra con la cual convivimos, y respetarla en su alteridad.

\section{Sobre indigenas al sur de América Latina}

En el caso de Chile, que posee una de las últimas regiones prístinas del mundo en la Reserva de la Biosfera Cabo de Hornos (Rozzi et al. 2012), nos encontramos con el desafío de superar la imagen exótica de los pueblos indígenas fueguinos. Durante el siglo XIX, sus retratos quedaron plasmados como imágenes-fotos de los Zoológicos Humanos inventados en Europa para exhibir y "estudiar científicamente" las supuestas costumbres exóticas de nativos de diferentes partes del mundo (Báez \& Mason, 2006). Grupos indígenas del sur de América fueron raptados y enjaulados para ser expuestos en ciudades europeas como parte de un espectáculo inhumano. La minusvaloración, el insulto, el maltrato y la falta de ética hacia los nativos del sur y de varias otras partes del mundo, constituyeron en general la mirada exotista imperial sobre el paisaje y los cuerpos del Nuevo Mundo del sur del continente.

Para superar la distorsión de tradiciones

guerreaban entre sí y los prisioneros morían en rituales antropofágicos. Los descendientes de los tupí constituyen hoy las etnias contemporáneas de Brasil. 
culturales y la opresión colonialista de los pueblos nativos, las ideas filosóficas ambientales de pensadores chilenos, como Ricardo Rozzi, hacen parte de un nuevo espíritu igualmente post-exotista centrado en enfocar la importancia que tienen los sujetos originarios al sur del continente americano con sus conocimientos sobre la naturaleza (Rozzi, 2001). Rozzi encuentra convergencias notables entre las formas de conocimiento ecológico ancestral de pueblos originarios y el de las ciencia ecológicas y evolutivas contemporáneas. La construcción de una nueva identidad socioambiental dignifica a los pueblos originarios, quienes ya no son vistos como ignorantes, sino como personas con conocimientos importantes -inteligentes y creativos- para la ecología y mucho más. Sus hábitos de vida para co-habitar con la diversidad de especies biológicas en su hábitats establecen formas sustentables y respetuosas de relacionarse con los cohabitantes no humanos (Rozzi, 2015a). Estos hábitos de vida ofrecen claves para pensar en una ética biocultural y en una educación biocultural ambiental donde se revaloren saberes ancestrales, que implican, por ejemplo, relaciones de parentesco evolutivo de los seres humanos con sus parientes alados y con la naturaleza toda (Rozzi, 2014). Estas relaciones de parentesco son captadas también por una renovación hermenéutica-ecológica-cristiana en una especie de franciscanismo-indigenismo o indigenismo-franciscano que enfatiza un cristianismo latinoamericano, la hermandad de los hombres con la naturaleza. El sol, la luna, las aves, los pájaros son co-habitantes cruciales tanto para la ética biocultural y la filosofía sur-ecológica como también para nuevas tradiciones cristianas asociadas a la eco-teología de la liberación y al pensamiento indígena, asunto plasmado también en su expresión poética (Rozzi, 2012b).

El poeta mapuche, Lorenzo Aillapan, trabajando en conjunto con Ricardo Rozzi, preparó una selección de poemas (Aillapan \& Rozzi, 2001) que incluyen alusiones onomatopéyicas del diálogo inter-especies: entre aves y humanos. Los poemas bilingües mapudungun-español aluden al mismo tiempo a una genealogía común. Por ejemplo, respecto al ave rapaz Traru (Caracara plancus), Aillapan escribe (Aillapan \& Rozzi, 2004, p. 246):
Wefünmeu weda inautun dungu tachi LofmeuFemngechi wïne kimfaluwi rupayawiyum wera traru

kiñeina may pi pu che mülerkeyay tachi fütra

Aukan akulu deuma ka tripaye che Lofmeu

Fey kiñe weche tuy traru ünüm ñi püllü pepilkawi

Wüne Leftraru che wefrumey, feychi üy tukuy.

¡Trarrrr trarrrr traruuuu traruuuu!

En la comarca para la gente anuncia desgracia.

Varios traros detectan visiones entre la gente,

entonces los comuneros comentan y vociferan: "así

la guerra vienen a causar los afuerinos en la Comarca".

Un joven, con nombre de Traru, su veloz espíritu incorpora,

figura novedosa, primer nombre se transforma en Lautaro.

¡Trarrrr trarrrr traruuuu traruuuu!

(Aillapan \& Rozzi, 2004, p. 426)

Este poema sobre el Traru alude a un guerrero milenario que pertenece al linaje de las águilas y que dio origen al más grande de los guerreros mapuche, Lautaro, cuyo nombre significa traru veloz. Es decir, "Traru se transforma en Lautaro", haciendo alusión de la relación con los hombres con las águilas y a su admiración del vuelo veloz de estas aves (Aillapan \& Rozzi, 2004, p. 430).

De esta manera, las historias genealógicas de las aves se entremezclan con aquellas genealogías de los seres humanos. La cosmogonía mapuche y la teoría científica de la evolución biológica convergen al afirmar un origen común para todos los seres vivos y proponer, por tanto, un grado de parentesco genealógico entre las aves y los seres humanos, familiaridad que la poesía de Aillapan logra transmitir a su comunidad desde un leguaje creativo y no técnico (Rozzi, 2014).

\section{Homogeneización y exotismo biocultural}

El concepto de homogeneización biocultural se refiere a la homogeneización interrelacionada 
de los hábitats y hábitos de vida (Rozzi, 2013). Implica una sustitución de las ricas diversidades biológicas y culturales originarias de cada región por una uniformidad de biota y cultura que se impone globalmente a partir del colonialismo occidental iniciado en la modernidad (Rozzi, 2012a). Este proceso alude a la tendencia occidental uniformadora que hoy, con la globalización hegemónica, impone como ideología su propia visión o hermenéutica uniformadora a todas las localidades afectando tanto a la biodiversidad ecosistémica como a la diversidad cultural de cada lugar del planeta.

La homogeneización biocultural $\mathrm{O}$ el exotismo biocultural nos hablan del peligro de las tendencias ideológicas, semánticas, estéticas y políticas propias de la globalización occidental en su hegemonía colonialista, global, política, científica y comercial. El exotismo biocultural alimenta una tendencia neo-ecocolonialista que tiende a homogeneizar toda la diversidad biótica y la cultural de una región al imponer la ideología de lo occidental sobre lo regional (Rozzi 2015b). La imposición de lo foráneo sobre lo local provoca la reducción o la eliminación de la riqueza biótica y cultural local-diversa. En consecuencia, la homogeneización biocultural conlleva pérdidas de conocimientos locales, regionales, que son valiosos para afrontar la actual crisis ecológica (Rozzi, 2015b).

La interpretación del mundo por el exotismo biocultural occidental implica que todos debemos ser iguales, todos debemos estar uniformados. Y solo un "único modelo" es el que se debe seguir: el occidental. Para el exotismo del "ojo occidental imperial", las diferencias y las otredades son rechazables. Se impone, en cambio, un modelo estético y epistemológico foráneo único que debe ser adoptado (Paredes, 2017). De acuerdo a Rozzi, preservar, mantener y conservar la diversidad biocultural es lo que debe importar en cada región frente a la tendencia de la homogeneización occidental que oculta $e$ invisibiliza la diversidad biológica, cultural, estética y lingüística de cada región, de cada paisaje, de cada pueblo. Rozzi plantea que una educación biocultural ambiental centrada en lo local podría tener el efecto de erradicar un colonialismo epistemológico, ecológico y cultural, que lleva al desconocimiento de lo que inmediatamente rodea a los pueblos originarios y a las comunidades locales (Rozzi et al. 2008). La homogeneización o exotización propia de la globalización occidental centrada en la tendencia de la unificación del mercado y uniformización de la vida, no está interesada en cuestiones ecológicas ni culturales o sociales regionales, sino más bien exclusivamente en los fines comerciales y de inserción política en cada región (Paredes, 2017). De ahí que, a su vez, las políticas neoliberales que imperan hoy a escala global, no estén interesadas en las costumbres o en los modos de relación de los pueblos con su región (Rozzi, 2015b). "El "ojo occidental globalizador" tiende a erradicar las diferencias a nivel global e intenta uniformarnos a todos hacia su "modelo de vida, de ser y de actuar".

Es importante distinguir el concepto de exotismo en biología y en estudios culturales. La ecología contemporánea, en su juego de lenguaje científico, hace referencia a las pérdidas de la diversidad biológica de un ecosistema regional asociada al arribo y a la expansión de especies exóticas invasoras (Crego et al . 2018). En contraste, el exotismo cultural hace referencia a la pérdida de la diversidad cultural: al extinguirse un pueblo, se pierden sus saberes ecológicos y se olvidan valiosos conocimientos ambientales y culturales. En este caso, se trata de la pérdida de grandes legados de tradiciones culturales que son sustituidas por la tendencia cultural global exotista. Además, el exotismo cultural hoy estaría hablándonos de los muros físicos y lingüísticos, en que el idioma del otro tiende a ser negado por negar "al otro": al oriental, al latinoamericano, y a otros. Al imponer muros y no puentes, debido al "ojo imperial exotista" se pierde el horizonte de una comunidad humana amplia, un horizonte cosmopolita y multicultural donde todos aprendemos de todos.

\section{Sobre "encantamientos" o de la sacralización de la naturaleza americana}

En Bolivia, uno de los países con una rica herencia cultural sobre la naturaleza, encontramos la filosofía (también teología) de la Pachamama o Pachasofía (Estermann, 2011). Esta filosofía se complementa en este artículo con la teoría del ecofeminismo, con el objeto de abordar tanto la cuestión local de la naturaleza americana como 
la cuestión ecológica más amplia de la tierra o Pachamama como universo.

El concepto de la América Latina exótica como un "cuerpo continental femenino violentado", se asocia con la imagen distorsionada y exótica del cuerpo-geografía de América que pretende imponer la conciencia occidental global en su homogenización biocultural cosificante, mecánica y destructiva sobre la Tierra. Por eso, un concepto alternativo de cuerpo-tierra o cuerpo-mundo es clave para la comprensión ecológica post-exótica en nuestros días. La teóloga boliviana Vicenta Mamani propone un planteamiento teológico de la Pachamama, según el cual la Madre Tierra es efectivamente un Gran Cuerpo sagrado. En términos de Mamani, la Pachamama:

es como el cuerpo material donde se nace, vive y al final se va a la otra vida misteriosa... Es Pachamama, como una madre que nos provee de todo para alimentarnos en abundancia y para vivir en fraternidad... Es la complementariedad por la reciprocidad... es todo lo que existe, y por eso todo le pertenece y se cumple en plenitud porque todo está previamente ordenado al ritmo de la vida... es el tiempo, el espacio, es el espíritu y la carne; la luz y oscuridad; arriba abajo. Tú, yo y nosotros en su totalidad... es como la placenta de una madre, donde hay vida plena para un pequeño ser viviente, que espera venir al mundo desde el vientre materno (Mamani \& Quispe Huanca, 2007, pp. 11-50).

El teólogo suizo-boliviano Josef Estermann, plantea una Pachasofia e interpreta que:

Pacha significa tierra, globo terráqueo, mundo, 'planeta', 'espacio de la vida, pero también universo, estratificación del cosmos... Cuando se trata de la 'tierra' como base de la vida, se usa en ambos idiomas la expresión Pachamama ('madre tierra') o simplemente Pacha... Filosóficamente pacha significa el universo ordenado en categorías espacio-temporales", pero no simplemente como algo físico y astronómico. Pacha también podría ser un equivalente homeomórfico del vocablo latino ese ('ser'); 'pacha es 'lo que es', el todo existente en el universo, "la realidad'... Pacha como 'cosmos interrelacionado' o 'relacionalidad cósmica' (Estermann, 2011, pp. 156, 157 y 158).

La Pachasofía no trata de una filosofía que hable exclusivamente de una cosmovisión particular y regional, sino de una filosofía universal. Tiene el alcance de ser una filosofía de la Pacha con implicancias globales porque, según Estermann, la Pachasofía es "una reflexión integral de la relacionalidad cósmica como manifestación de la experiencia colectiva andina de la "realidad" (Estermann, 2011, p. 158). Es una forma de pensar lo real en la que la Pacha, es decir, la Madre Tierra, es el fundamento. La filosofía andina de la pacha piensa a la comunidad de hombres y mujeres como una gran familia que vive bajo un solo techohogar. El universo es una casa. La Pachamama es Mama-Pacha, una morada o casa-cuerpo, la Madre Tierra.

A diferencia de la mirada cosificante, ultrajante y dominante de los "ojos imperiales" occidentales con su respectiva hermenéuticaideología exotista sobre el Nuevo Mundo , la mirada indígena sobre la naturaleza expone una hermenéutica no exotista sobre la misma geografía femenina. Esto genera un cambio semántico en grado sumo: desde el desdén o desamor dicotómico de Occidente, y desde un gran amor y respeto hacia la Madre Tierra o Pachamama de los nativos. Desde lo local, el tema de la Pachamama contrarresta la imagen de la hermenéutica de la maldición de la "América exótica", con su sinónimo la "gran puta naturaleza americana”. Desde lo universal, América Latina puede fungir como un nuevo centro eco-espiritual femenino de la Tierra, con grandes aportes en muchos niveles: jurídico, ético, estético, espiritual, etc. (Paredes, 2017).

\section{Sobre "el Paraíso" a defender}

En el caso de Ecuador, que es el primer país en reconocer derechos a la Madre Tierra o Pachamama en su Constitución, según Gudynas: 
la naturaleza o Pachamama es sujeto de los derechos que la Constitución le reconoce, y entre ellos se indican el "respeto integral a su existencia", el "mantenimiento y regeneración de sus ciclos vitales, estructuras funciones y procesos evolutivos; la "restauración y mitigación de las consecuencias ambientales nocivas", y "la integridad del patrimonio genético nacional y la permanencia de la diversidad biológica y ciclos naturales" (Gudynas, 2009, p. 195).

El tema del reconocimiento de la naturaleza como sujeto de derecho en nada se contrapone a los derechos de los hombres, contribuye más bien a que los hombres y las mujeres del sur sean visibilizados y sus derechos queden resguardados. De ahí que la objetivación de la naturaleza en el antropocentrismo implique siempre la objetivación y la cosificación de los seres humanos. El biocentrismo latinoamericano pone de manifiesto que la defensa de la naturaleza como un gran sujeto no cae en la objetivación de los seres humanos. Porque implícitamente, como nos dice la fenomenología del cuerpo (MerleauPonty, 1975), debemos recordar que el humano es cuerpo y, por eso, es parte del paisaje. Ello apunta a una nueva formulación ontológica del paisaje-cuerpo llamada Florestanía (Gudynas, 2009, p. 171) ${ }^{7}$. Implícita y filosóficamente se llega a la comprensión de que el mismo humanocuerpo es parte del paisaje corporal geográfico porque es cuerpo. Donde Ser es ser Paisaje. Esta filosofía es la fundamentación de otra filosofía, la del "Buen Vivir" o Sumak Kawsay, que hace referencia a la vida digna del sujeto del sur desde ser parte de la Pachamama (Acosta et al. 2009) El "Buen Vivir" o "Suma Qamaña" es una filosofía que piensa en un desarrollo alternativo al occidental, que respeta y siempre tiene presente como límite a la Pachamama. Un nuevo autoconocimiento humano se revela como

7 "La Florestanía es una ciudadanía de la selva. Encierra una referencia a un contexto ecológico preciso: los ecosistemas de la selva tropical Amazónica. En esa zona existen distintos grupos humanos como indígenas o seringueiros, que han aprovechado esos ecosistemas sin destruirlos, mientras que sus propias prácticas se han adaptado a esos ambientes. Así pues, existe una íntima asociación entre ese contexto una nueva sabiduría eco-ontológica post-exótica, como modo de vida que emerge desde el sur.

\section{CONCLUSIONES: SOBRE EL GIRO HACIA EL SUR}

Hoy nuevamente aparece el exotismo biocultural, es decir, el exotismo sobre la geografía y sus habitantes de la región; un exotismo sobre lo ambiental y lo corporal. Arraigado en el mito exótico sobre los paisajes y los cuerpos de la "América exótica", se transfigura nuevamente al sur hacia un exotismo social y ambiental de América Latina. Pero también hoy en América Latina, desde el postexotismo se subraya la superación del exotismo ambiental y social. De esta forma podrá apreciarse sin prejuicios, estereotipos, engaños o imágenes deformadas, todo un ámbito de conocimientos a nivel cultural, biológico, ecológico y humano en la construcción de un futuro de cara al cambio climático global y frente a la era de tecnologías que imponen la artificialidad materialista, que tienden a suplantar lo natural con lo artificial: al cuerpo humano y a la naturaleza con las máquinas o los robots. La técnica o techne ha dejado de ser una extensión del hombre para ser una suplantación del mismo. No es "el extranjero" sino la máquina, el fondo tecnológico del nuevo exotismo tecnológico que suplanta al "otro hombre" con un robot. Un nuevo exotismo, basado en el supuesto miedo al otro, prefiere al robot para que lo suplante.

El aporte que podemos rescatar en este trabajo y desde América Latina, especialmente desde el "ecofeminismo del sur", es la comprensión de la naturaleza como un Gran Cuerpo en el cual habitamos. Este cuerpo-geográfico-femenino ha sido penetrado con violencia, y este daño geocorporal lo ha llevado a un estado de gravedad y enfermedad tal, que la salud ecológica-corporal de la Tierra-cuerpo de la Pachamama necesita ahora una "eco-medicina" que considere todos los ámbitos de la comprensión biológica-ecológica,

ecológico y las prácticas sociales; uno no es posible sin el otro... Devastar la selva es también destruir la propia esencia de la ciudadanía ecológica de los florestanos... La clásica división de la modernidad entre sociedad y naturaleza se hace muy borrosa bajo la propuesta de florestanía, ya que una necesita de la otra, y una contiene la otra... Se trata de una meta-ciudadanía ecológica". 
antómica-geográfica, cultural, filosófica y espiritual de manera complementaria.

Para la sociedad global, la filosofía de la Pachamama representa un gran aporte. La ecología internacional actual podría nutrirse de las filosofías ambientales locales del mundo, con sus respectivos conocimientos ecológicos diversos, que ofrecen conocimientos singulares acerca de las relaciones respetuosas y responsables entre los seres humanos con la Tierra (Callicott, 2017). Superar la herida colonial sobre el gran cuerpo de la Madre Tierra americana, también llamada Pachamama, nos habla de la necesidad de retomar una ética eco-amorosa hacia la naturaleza, desde el sur-eco-erotismo (Callicot, 1997).

\section{AGRADECIMIENTOS}

La preparación de este artículo ha contado con el apoyo de los proyectos CONICYT PFB- 23 y Apoyo a Centros Científicos y Tecnológicos de Excelencia con Financiamiento Basal CONICYT AFB170008.

\section{BIBLIOGRAFÍA}

Acosta, A., Lander, E., Gudynas, E., Wray, N., Leon, M., Quintero, R., Carrere, R.,... \& Houtart, F. (2009). El Buen Vivir. Una Vía para el Desarrollo. Quito, Ecuador: Ediciones Abya Yala.

Aillapan, L., \& Rozzi, R. (2001). Veinte Poemas Alados de los Bosques Nativos del Sur de Chile. México: Editorial Plaza y Valdés.

Aillapan, L., \& Rozzi, R. (2004). Una etno-ornitología mapuche contemporánea: poemas alados de los bosques nativos de Chile. Ornitología Neotropical, 15, 419-434.

Báez, C., \& Mason, P. (2006). Zoológicos Humanos. Fotografías de Fueguinos y Mapuche en el Jardín D'acclimatation de París, Siglo XIX. Santiago, Chile: Pehuen.

Callicot, J. B. (2017). Cosmovisiones de la Tierra. Un Estudio Multicultural de Éticas Ecológicas desde la Cuenca del Mediterráneo hasta el Desierto Australiano. México: Plaza y Valdés.

Callicott, J. B. (1997), Earth's Insights: A Multicultural Survey of Ecological Ethics from the Mediterranean Basin to the Australian Outback. Berkeley, California: University of California Press.

Chavarría, M. J. (2013). Construcciones/Invenciones: de la
Suiza Centroamericana al País más Feliz del Mundo. San José de Costa Rica: Museo de Arte y Diseño Contemporáneo, MADC.

De Alencar, J. (2000). Iracema. Málaga, España: Ediciones Obelisco.

Espinosa, Y. (2009). 12 de octubre: conmemorar la violación originaria”. Publicado en Suplemento Pan y Rosas No. 12, Argentina, Septiembre.

Estermann, J. (2011). Filosofía Andina. Sabiduría Indígena para un Mundo Nuevo. La Paz, Bolivia: Instituto Superior Ecuménico Andino de Teología -ISEAT.

Galeano, E. (2011). Las Venas Abiertas de América Latina. México: Siglo XXI.

Giraudo, V. (2016). Antropofagia y Modernidad. Arte Brasileño en la Colección Fadel. Buenos Aires, Argentina: MALBA; México: Museo de Arte Nacional.

Grün, M. (2012). Ética e Educação Ambiental: a Conexão Necessária. Campinas, Sao Paulo, Brasil: Papirus.

Gudynas, E. (2009). El mandato Ecológico. Derechos de la Naturaleza y Políticas Ambientales en la Nueva Constitución. Quito, Ecuador: Ediciones Abya Yala.

Mamani, V., \& Quispe-Huanca C. (2007). Pacha. Bolivia: Verbo Divino.

Merleau-Ponty M. (1975). Fenomenología de la Percepción. Barcelona, España: Ediciones Península.

Mignolo, W. D. (2007). La Idea de América Latina. La Herida Colonial y la Opción Decolonial. Barcelona, España: Gedisa.

Núñez, F. (2002). La Malinche, de la Historia al Mito. Divulgación serie Historia. México: Instituto Nacional de Antropología e Historia.

Paredes, A. (2017). América Latina Exótica: Hermenéutica Ecoestética de la Naturaleza y el Cuerpo. Una Aproximación al tema. Tesis Doctoral en Filosofía, Instituto de Investigaciones Filosóficas Luis Villoro, Universidad Michoacana de San Nicolás de Hidalgo, Morelia, Michoacán, México.

Pratt, L. M. (2010). Ojos Imperiales. Literatura de Viajes y Transculturación. México: Fondo de Cultura Económica.

Primack, R., Rozzi, R., Feinsinger, P., Dirzo, R., \& Massardo, F. (2001). Fundamentos de Conservación Biológica: Perspectivas Latinoamericanas. México D.F: Fondo de Cultura Económica.

Rozzi, R. (2001). Éticas ambientales latinoamericanas: raíces y ramas. En R. Primack, R. Rozzi, P. Feinsinger, R. Dirzo \& F. Massardo (Eds.), Fundamentos de Conservación Biológica: Perspectivas Latinoamericanas, (pp. 311362). México: Fondo de Cultura Económica. 
Rozzi, R., (2012a), Biocultural ethics: the vital links between the inhabitants, their habits and regional habitats. Environmental Ethics, 34, 27-50.

Rozzi, R. (2012b). South American environmental philosophy: Ancestral Amerindian roots and emergent academic branches. Environmental Ethics, 34, 343-365.

Rozzi, R. (2013). Biocultural ethics: from biocultural homogenization toward biocultural conservation. En R. Rozzi, Pickett, S. T. A., Palmer, C., Armesto, J. J., Callicott, J. B. (Eds.), Linking Ecology and Ethics for a Changing World: Values, Philosophy, and Action, (pp. 9-32), Ecology \& Ethics Book Series. Dordrecht, The Netherlands: Springer.

Rozzi. R., Arango, X., Massardo, F., Anderson, C., Heidinger, K., \& Moses, K. (2008). Field environmental philosophy and biocultural conservation: the Omora Ethnobotanical Park educational program. Environmental Ethics, 30, 325-336.

Rozzi, R., Massardo, F., Anderson, C. McGehee, S., Clark, G., Egli, G., Ramilo, E.,... Zárraga, C. (2010). Multi-Ethnic Bird Guide of the Sub-Antarctic Forests of South America. Denton, Texas and Punta Arenas, Chile: University of North Texas Press-Ediciones Universidad de Magallanes.

Rozzi, R., Armesto, J. J., Gutiérrez, J., Massardo, F., Likens, G., Anderson, C. B., Poole, A.,... Kalin, M. T. (2012). Integrating ecology and environmental ethics: earth stewardship in the southern end of the Americas.
BioScience, 62(3),226-236.

Rozzi, R. (2014). Implicaciones éticas de narrativas yaganes y mapuches sobre las aves de los bosques templados de Sudamérica Austral. En R. Rozzi \& J. Jiménez (Eds.), Ornitología Subantártica de Magallanes. Primera década de Estudios de Aves en el Parque Etnobotánico Omora, Reserva de Biosfera Cabo de Hornos, Chile. Ediciones Universidad de Magallanes University of North Texas Press.

Rozzi, R. (2015a). Earth stewardship and the biocultural ethic: Latin American perspectives. En R. Rozzi, F. S. Chapin, J. B. Callicott, S. T. A. Pickett, M. E. Power, J. J. Armesto \& R. H. May Jr., (Eds.), Earth Stewardship: Linking Ecology and Ethics in Theory and Practice, Ecology \& Ethics Book Series (pp. 87-112). Dordrecht, The Netherlands: Springer.

Rozzi, R. (2015b). Implications of the biocultural ethic for earth stewardship. En R. Rozzi, F. S. Chapin, J. B. Callicott, S. T. A. Pickett, M. E. Power, J. J. Armesto \& R. H. May Jr., (Eds.), Earth Stewardship: Linking Ecology and Ethics in Theory and Practice, Ecology \& Ethics Book Series (pp. 113-136). Dordrecht, The Netherlands: Springer.

Said, W. E. (2016). Orientalismo. México: Penguin Random House

Segalen, V. (1989). Ensayo Sobre el Exotismo. Una Estética de lo Diverso (y Textos sobre Gauguin y Oceanía). México: Fondo de Cultura Económica. 